\title{
Does School Average Achievement Explain the Effect of Socioeconomic Status on Math and Reading Interest? A Test of the Information Distortion Model
}

\begin{abstract}
Based on the Information Distortion Model (IDM), we hypothesized higher academic interest among low socioeconomic (SES) Australian children compared to equally able high SES Australian children. We extend the IDM in two ways. First, the IDM is a model of school selection and thus empirical evidence of its effect needs to come from a model that controls for achievement prior to school selection. Second, the mechanism of the IDM is presumed to be the big-fish-little-pond-effect (BFLPE), which has not been tested. We used a longitudinal representative sample of first-year high-school students (age $\sim 12, \mathrm{~N}=2,507$ ). We linked student high-school survey data to the whole of school and individual student administrative records of achievement from high-stakes national standardized tests in elementary and highschool. Our results were consistent with IDM for math interest but more mixed for reading interest, suggesting that additional processes may be in operation.
\end{abstract}

Keywords: Educational Inequality; Information Distortion Model; Math; Reading

Scripts can be downloaded from the OSF project for this paper. 
Some research shows that relative poverty is associated with poor academic motivation (Swift, 1966). Considerable research has aimed at articulating the particular environmental pressures that shape the motivation of children from low socioeconomic status (SES) backgrounds. For example, research argues that poverty forces young people to focus on the short-term. This hard-wires young people against effective self-regulation (Guthrie et al., 2009). While such research provides evidence of the negative effect of poverty on some psychological factors, it does not follow that all children from lower SES backgrounds will have a deficit on all motivational factors related to academic achievement and attainment.

In this paper, we argue that low SES children may have higher academic interest than similarly achieving high SES children in stratified school systems. This is because a child's relative position in their school is instrumental to the development of academic interest (Marsh et al., 2020). Given that low SES children tend to enroll in less competitive schools than equally able high SES children, they may have a slight advantage in interest because of their relatively better in-school position. This process is called the Information Distortion Model (IDM; Parker et al., 2018). Our aim is to test the precepts of IDM for children's academic interest. Unlike previous IDM research, we provide controls for academic achievement in national standardized tests prior to high-school enrollment. This is critical given the IDM is a model focused on school selection processes, and elementary achievement influences high-school enrolment.

In this paper we focus on children's academic interest in math and reading. Gutman and Schoon (2016) highlight interest as a critical non-cognitive skill to target to help resolve educational inequality. Here we focus on interest defined as individual interest or a child's preference for engaging in activities related to a given academic domain (Hidi, 1990). Interest 
includes feelings of engagement, is specifically related to the content of a given academic domain, and is strongly related to other emotions like enjoyment, joy, and excitement (Hidi \& Renninger, 2006; Pekrun, 2019). Academic interests are considered to be an important facet of intrinsic motivation and predictor of academic attainment (Eccles \& Wigfield, 2002, 2020; Ryan \& Deci, 2000).

While Gutman and Schoon (2016) show convincing evidence that motivation is related to attainment, they do not show that children from low SES backgrounds are necessarily deficient in it. Likewise, philanthropic organizations run motivation interventions based on the link between motivation and attainment but without considering if disadvantaged children have a deficit in such constructs (e.g., The Smith Family, 2016). Thus, we focus on the construct of academic interest because we believe it has been promoted as a means of reducing inequality in educational attainment without careful attention to how, why, and under what circumstances low SES children might need such an intervention. We focus on the academic domains of math and literacy as basic skills in education that have been shown to have significant effects on employability, employment, and wages (Dearden et al., 2000).

\section{Information Distortion Model}

The IDM argues that neither academic interest nor positive self-evaluations can be a major driving force behind educational inequality because low SES children report greater levels of these constructs when compared to equally able high SES children (Parker et al., 2018). The IDM links the social comparison theory of Marsh and Parker (1984) with a concern about school stratification (Parker et al., 2018; Parker et al., 2016). According to the IDM, there are two mechanisms that link SES to academic interest. The first mechanism 
focuses on the advantage that children from high SES backgrounds have over low SES children in their academic cardinal achievement (i.e., their actual scores on standardized tests; Boudon, 1974; Reardon, 2011). This mechanism leads to an expected positive link between SES and academic interest via academic ability. This mechanism indicates that high SES children tend to have higher academic achievement (Reardon, 2011). And because children are interested in things they are good at (Eccles \& Wigfield, 2002, 2020; Jansen et al., 2016; Schiefele et al., 1992), children from high SES backgrounds have higher academic interest.

The second mechanism focuses on the influence of SES on academic interest conditioned on achievement. Put simply, this mechanism explores the difference in interest for high and low SES children of equal academic achievement but in different school contexts. Here children from low SES backgrounds gain a small advantage over children from high SES backgrounds in academic interest due to being enrolled — on average - in poorer performing schools. Put simply their relative achievement (position in their school) tends to be higher given the same level of cardinal achievement (the same score on a standardized test). This mechanism is a function of the social comparison processes of the Big-Fish-Little-Pond effect (BFLPE: Marsh \& Parker, 1984). This mechanism focuses on differences in academic interest between high and low SES children of similar levels of academic ability who attend schools with different achievement contexts.

Parker and colleagues (2018) argue that in school systems that are stratified by both achievement and SES, low SES children may have higher levels of factors like academic selfconcept and interest than equally able high SES children. When a country stratifies its pupils by ability, brighter children tend to be schooled together. Yet school systems do not select 
children on the basis of achievement alone (Maaz et al., 2008). Ability stratification is enmeshed with socioeconomic stratification (see Figure 1). High SES parents tend to enroll their children in schools with higher average ability. Low SES parents tend to select their children into schools with lower ability (Checchi \& van de Werfhorst, 2018; Goldthorpe, 2006; Maaz et al., 2008). Matched on ability, this results in children from low SES backgrounds being 'under-matched': attending a school with lower average achievement than would be expected based on their elementary academic achievement alone. In contrast, equally able high SES children tend to be 'over-matched': attending a school with a higher average ability than would be expected based on their elementary academic achievement alone.

Parker and colleagues (Parker et al., 2018) tested this theory in multiple countries that differed in the degree to which the school system was stratified by achievement. They showed that: a) the total effect of SES on psychological factors favored high SES children; b) when considering equally able children, however, children from low SES backgrounds had an advantage in academic self-beliefs, interest, and utility value motivation (the largest effects being present for academic interest—-the focus of the current study); and c) the size of this advantage was larger in school systems with implicit (e.g., Australia) and/or explicit (e.g., Germany) achievement and social stratification; which they assumed was due to larger BFLPEs (Marsh \& Parker, 1984) - the negative relationship between school average achievement and an individual child's self-beliefs, interest, and other motivation factors.

In our study, we focus on Australia which has a variety of implicit and explicit tracking mechanisms including enrolment based on geographic stratification (i.e., school catchment areas), some selective schooling, and extensive private schooling. As a result, Australia has 
relatively high levels of both achievement and social stratification (see Figure 1). It is important to note that the IDM is agnostic to the mechanisms that give rise to stratification; that is, it does not matter whether stratification is implicit, explicit, or both. Rather, it only matters that stratification in an education system exists.

The findings of Parker and colleagues (2018) provided evidence in favor of the IDM. Yet there were several limitations of this research. First, they used data from the Programme for International Student Assessment (PISA). PISA achievement tests are low stakes. This is a concern because there are estimates that approximately $25 \%$ of PISA participants do not take the test seriously and high SES students are overrepresented among non-serious participants (Akyol et al., 2019). This may bias IDM findings by reducing the association between achievement and SES. Second, PISA uses student reported estimates of SES which may be of questionable quality. Third, the authors focused on math only. And most importantly, they had no controls for achievement prior to high-school selection.

Given that the IDM is a theory of the effect of achievement and socioeconomic school selection, it is critical to show that the relationships the IDM imply are present when controlling for achievement prior to high-school selection. This is because: a) children's achievement is linked to school selection, and the IDM is a model of schools selection; $b$ ) children may adjust their effort on achievement tests in high-school in response to their relative position in their high-school Year (Jackson et al., 2006); and c) achievement and interest are reciprocally related (Koller et al., 2001).

Parker and colleagues (2018) also assumed rather than tested the presence of the mechanisms thought to give rise to the IDM. They claimed that the BFLPE is the main mechanism behind the IDM. Yet there is no empirical evidence for this assertion. The claim 
to be tested is that a child from a low SES background will have greater academic interest than an equally able child from a high SES background. This is because the low SES child would be more likely to be enrolled in a school where the average academic achievement is lower. This would mean the low SES child would be more likely to be among the better performers in their grade than would their equally achieving high SES peers and would thus benefit from the influence of the BFLPE.

\section{The Big-Fish-Little-Pond Effect and the Information Distortion Model}

The BFLPE links students' tendency to compare themselves with others with the tendency of society to select children — whether implicitly or explicitly_into schools based on achievement (Marsh \& Parker, 1984). Children's interest is moderately to strongly related to their academic ability (Schiefele et al., 1992). Yet, because they compare themselves against children in their immediate setting (Zell et al., 2017), the average ability of the school has an independent and negative effect on interest.

The BFLPE suggests that individual academic self-concept, interest, and related variables are mostly a function of achievement as measured by external reference standards like tests and grades. But these same variables are not just dependent on cardinal performance scores. Rather, local rank or relative position matters (Murphy \& Weinhardt, 2020). Young people typically form their self-beliefs based on their relative position (Marsh, 2007). So strong is this tendency that students appear to form their beliefs relatively even when specific ordinal rank feedback is unavailable to them (Murphy \& Weinhardt, 2020). Although the BFLPE is often estimated with respect to academic self-concept, it has been shown to generalize to multiple other academic psychology constructs including academic interest (Marsh et al., 2020). 
The BFLPE can be described counterfactually. Suppose the parents of a child of average ability are given the choice of sending her to one of two schools. The first is an academically selective school where the child's ability will put her in the lower end of the achievement distribution. The second is a local high-school where the child's ability would put her among the best performers in her school. The BFLPE argues that the child will have a significantly lower academic self-concept in the selective school than in the local highschool.

The BFLPE depends on schools being stratified by achievement. Were children to be truly randomly assigned to schools, the average achievement of all schools would be roughly equal, and no BFLPE effect would emerge. In contrast, the more countries stratify by ability, the larger are BFLPE effects (Parker, Dicke, et al., 2019; Salchegger, 2016). Yet school systems that stratify by academic ability do so imperfectly. Academically stratified school systems also tend to be socially stratified. High SES children will be over-matched and low SES children will be under-matched (Parker et al., 2018). The implication of this school selection process is that low SES children might receive a small advantage in terms of academic interest, motivation, and self-concept when compared to equally able high SES children. And this is due to the BFLPE.

The BFLPE is the main process underlying the IDM. The BFLPEs link to the IDM is through two forms of 'distortions.' The first is a general human bias that prefers information from local sources (Murphy \& Weinhardt, 2020). This means that students tend to rely on the information they receive from their class and school in forming opinions about themselves and about academic content. The second form of 'distortion' is that school achievement stratification means that the relative-position-information that students get from their local school context is not an accurate reflection of their ability relative to all similar aged children 
in the country. This leads children in high performing schools to think worse of themselves than their test scores suggests they should.

Thus, the IDM hypothesis that SES influences academic interest, motivation, and selfconcept via an achievement mechanism (this is the primary effect in Boudon's [1974] theory). High SES children tend to have higher academic achievement (Parker, Guo, et al., 2019; Reardon, 2011). Yet, when comparing children with the same academic achievement, the BFLPE leads us to expect that low SES children may have more positive outcomes. These mechanisms are in conflict. If we assume, based on previous BFLPE research, that the individual level effects are stronger than the BFLPE effect, then the total effect of SES on interest should be positive. Yet when controlling for academic ability we would expect the relationship between SES and academic interest to change ${ }^{1}$ from positive to negative. The IDM assumes this change in the direction of SES association is due to the BFLPE. Thus, controlling for school average achievement — that is the BFLPE — the relationship between SES should attenuate toward zero. The reason for this has to do with the conditions that this model implies. In this model the effect of SES on interest is based on equally achieving children in equally achieving schools and thus removes the influence of school selection effects that are the focus of the IDM².

\section{IDM and its Implied Counterfactuals}

The IDMs central claims can be simplified by a set of three comparisons between a low SES and a high SES child, compared under increasingly similar circumstances.

\footnotetext{
${ }^{1}$ Here we refer to change not in a temporal or longitudinal sense but in relation to how the size and direction of the association of SES on academic interest changes under different modelling specifications.

2 The BFLPE can be fit to either school-average achievement or class-average achievement with the latter being stronger (see Marsh et al., 2016). But the IDM focuses on the BFLPE at the school level because it is focused on the influence of school selection mechanisms on children's self-beliefs and motivational factors.
} 
1. Comparison 1: Comparing a high SES and a low SES child chosen randomly from the population, the IDM expects the high SES child to have higher academic interest than the low SES child. The mechanism reflects the well-established finding that SES is positively associated with academic achievement (Reardon, 2011) and achievement is positively related to interest (Jansen et al., 2016).

2. Comparison 2: Comparing a high SES and a low SES child of equal achievement on a standardized test, the IDM expects the low SES child to have greater academic interest than the high SES child. Here, the mechanism is the tendency for children from more advantaged backgrounds to be enrolled in higher average achievement schools and thus their academic interest is suppressed by the BFLPE.

3. Comparison 3: Comparing an equally achieving high SES and low SES child in the equally achieving schools, the IDM would suggest that there would be no difference in the two children's academic interest.

Putting these comparisons into a set of simplified regression models, we would expect the association of SES with interest would be significantly positive in a model with just SES (Model 1 reflecting Comparison 1); negative in a model with SES and measures of academic achievement (Model 2 reflecting Comparison 2); and zero in a model with SES, academic achievement, and school average achievement (Model 3 reflecting Comparison 3).

These comparisons reveal a potential limitation in the IDM. Namely, the issue that is made clear is that they assume that the association between SES and academic interest is due to achievement differences and the BFLPE; a contrast social comparison mechanism.

\section{Alternative Processes: Assimilation in Social Comparison Theory}


Contrast effects are only one social comparison mechanism. The other is assimilation ${ }^{3}$ (Jerrim \& Sims, 2019). One form of assimilation is the "basking-in-reflected-glory" effect. This is the boost that children receive to their self-beliefs and motivation from their membership of an elite school or group (Marsh et al., 2000). Other forms of assimilation include internalizing stereotypes based on some aspect of identity. For example, internalizing the idea that girls are bad at math or boys are bad at reading (Parker et al., 2017). In relation to SES, internalization can come from assimilating to peer, parent, or community socialization associated with one's social status (Gambetta, 2009). Thus, children from lower SES backgrounds may actually have lower academic interests because they come to believe "kids like me are not interested in school" (see Akerlof \& Kranton, 2005). If such assimilation mechanisms were in operation, what sort of effect would we expect it to have on the comparisons above? We would expect a latent assimilation influence to increase the positive association between SES with academic interest.

\section{Potential Patterns of Results}

Running models related to these comparisons above in a set of three regression models, the following patterns of results are possible:

1. Pattern 1 (the null pattern): The association of SES with academic interest would be consistently non-significant. Or any pattern of parameters between model estimating comparison processes 1-3 (see above) that is inconsistent with the IDM (e.g., SES association with interest favouring disadvantaged children in a Model 1 but advantaged children in Model 2).

2. Pattern 2 (the pure IDM pattern): The association between SES and academic interest would have the exact pattern hypothesized by the IDM. In Model 1, the

\footnotetext{
${ }^{3}$ Assimilation is also used to refer to within person mechanisms in dimensional comparison theory and temporal comparison theory (Möller \& Marsh, 2013). Here we refer to assimilation only in relation to social comparisons.
} 
association would be significantly positive. In Model 2, the association would be significantly negative. In Model 3, it would be non-significant.

3. Pattern 3 (the IDM with assimilation pattern): In this pattern, the association would be most positive in Model 1, least positive in Model 2, and moderately positive in Model 3. The assimilation mechanisms would be latent (i.e., unobserved) in our model but could represent reflected glory, internalized stereotypes, and peer, parent, and community socialization effects described above.

\section{Current Research}

The current study aims to test the IDM process. To do this, we will use the Kindergarten cohort of the Longitudinal Study of Australian Children (LSAC; Sanson et al., 2002). Our research extends Parker et al.’s (2018) research in several ways.

First, the IDM is a model of school selection. Thus, it is critical to control for selection influences prior to high-school entry. We do this by including estimates of Year 3 and Year 5 (elementary) achievement from the high-stakes National Assessment Program Literacy and Numeracy (NAPLAN); the national standardized testing program that all Australian children undertake.

Second, Parker et al. (2012) assumed that the BFLPE was the main mechanism that explained the IDM but they provided no test of this. We do this by using school average achievement taken from the Year 7 NAPLAN data. Unlike most BFLPE studies, our use of government administrative data means that we have school average achievement from a highstakes achievement test from the child's complete school grade; thus avoiding potential issues related to sampling error so prevalent in school contextual effects research (Dicke et al., 2018). Sampling error refers to bias in aggregated variables that occurs when they are constructed from a sub-sample of the cases within a given cluster (Morin et al., 2014). 
Aggregated variables derived from subsamples can produce bias in multilevel models that include aggregated variables (e.g., models of the BFLPE). Sampling error with respect to the BFLPE can result in either over or under estimation of the influence of school average achievement on a given outcome (Morin et al., 2014).

Third, our models focus on children in Year 7; the first year of high-school. This means we are able to more clearly focus on the influence of being enrolled in a new school controlling for academic achievement from before high-school enrolment.

Fourth, we focus on the pattern of estimates in the association between SES and academic interest under different modelling conditions and thus are in a better position to understand the various mechanisms that might be at play.

Finally, we focus on both math and reading interests. The original Parker et al. (2018) paper only explored math. Focusing on multiple domains is important in order to get an idea of the generalizability of the IDM across academic domains.

Australia is a useful context for the current research, not only because it was a focus of the second study in Parker et al. (2018), but because data from the Programme for International Student Assessment places Australia as having approximately average levels of between school achievement and socioeconomic stratification (OECD, 2019; see Figure 1). Given that the IDM relies on the presence of both forms of stratification, Australia provides a useful test case.

Given the unique context of Australia, we controlled for a range of demographics that may be associated with school enrolment practices and could bias findings related to the IDM. First, Australia is one of four so-called 'traditional multicultural countries' along with Canada, the US, and New Zealand and, like these countries, has an Indigenous population 
that is educationally disadvantaged (Kymlicka, 2009). Both Language Other than English (LOTE) background and Indigenous status appear to be relevant to school enrolment (Sweller et al., 2012). Geography, particularly the rural/urban divide also influences school choice via a range of complicated factors that are both related to SES and separate from them (Campbell et al., 2009). Finally, we controlled for gender. It is unlikely that gender is related to school selection (though Australia does still have a small number of single-sex schools) but gender is relate to both academic achievement (Hyde \& Linn, 1988; Hyde et al., 1990) and interest (Parker, Van Zanden, et al., 2019).

\section{Method}

\section{Participants and Study Design}

Our primary data source was the Longitudinal Study of Australian Children-Kindergarten (LSAC-K; Sanson et al., 2002). LSAC provides survey weights that ensure that the sample is representative of the population at each time wave. We used the attrition and sample weights from the age 12 (Year 7) LSAC-K wave. LSAC is a stratified random sample of Australian children who were aged 4-5 in the year 2004. We linked child survey data with administration records at both the student and school level achievement data from NAPLAN. The total size was 2507 (48.9\% girls); $1.83 \%$ were Indigenous, $12.96 \%$ came from households that spoke a language other than English, and $34.98 \%$ were located in rural or remote Australian locations.

\section{Measures}

SES. To represent SES we used the Socioeconomic Position Index constructed by the LSAC survey organizers and collected when children were aged 4 years old (Baker et al., 2017). This index is constructed from parent reported standardized weekly income, years of 
education, and occupational prestige derived from the Australian Standard Classification of Occupations. The index has a mean of zero and a standard deviation of one.

Math and Reading Ability. Math and Reading at the child and complete school grade results were taken from administration records of NAPLAN test results. The NAPLAN tests we use were given to all eligible children in the country in Year 3 (age 8), 5 (age 10), and 7 (age 12); a further test in year 9 was carried out but was not yet included in the LSAC data at the time of analysis. The tests are scaled so they are comparable across age cohorts and across year grades. They have an Australian mean of 500 and a standard deviation of 100 across the full group of students from Year 3-Year 9. In our research, all achievement scores were standardized to have a mean of zero and a standard deviation of one.

Academic Interest. To measure children's liking of math/reading, we used the following item at age 12 (Year 7) "Do you like [math and number work/reading] at school?" with a response scale of 'no', 'sometimes', and 'yes'.

Controls. In all models, we control for urban/rural status, gender, Language Other Than English (LOTE), and Indigenous status as previous research has shown that not controlling for these factors can bias school context effects (Dicke et al., 2018). All demographic controls were collected at age 4. Basic descriptive, intraclass correlations, and distribution of all analysis variables can be found in Table 1. Correlations among study variables can be found in Table 2 .

\section{Statistical Analysis}

In predicting academic interest, we used multilevel proportional odds logistic regression, with a random intercept for school using the ordinal package in R (Christensen, 2019). Fixed effects were used for strata to account for the LSAC's sampling design. In LSAC, strata are based on statistical geographic regions designed to provide proportional representation of both cities and smaller population centers (Norton \& Monahan, 2015). 
Because of the use of attrition weights, missing data was small with the largest missing of $5.8 \%$ for Year 3 math and reading achievement records taken from government administrative data. All models were estimated using five imputations via the Multivariate Imputation by Chained Equations (MICE) package in R (Buuren \& Groothuis-Oudshoorn, 2011). We used a classification and regression tree model for multiple imputations, including all analysis variables in this model.

Results are reported in log odds and marginal predicted probabilities. Marginal predicted probabilities for a focal variable were calculated at the simple average for all other variables in the model. Thus, for example, we consider the probability of a child from a high SES background versus a low SES background for average achieving students. For illustrative comparison we describe the probabilities of responding Yes to our academic interest questions for a representative child with a high SES background (two standard deviations above the mean; hereafter high SES) and a child with a low SES background (two standard deviations below the mean; hereafter low SES). Marginal probabilities of Yes, Sometimes, and No across the full SES gradient are presented in figures.

Because model results can vary as a function of the modelling decisions that researchers make, we also fit a multiverse analysis with alternative modelling specifications (Steegen et al., 2016). The results of this analysis can be found in Figure 4 and show that our choices of covariates and modelling strategy (weights and correcting for data nesting) had little impact on our findings. Assumptions of proportional odds were tested by comparing models with category specific effects for SES versus a model without category specific effects. Results supported the assumption of proportional odds (see Appendix Table A1).

\section{Results}




\section{Math Interest}

The most common response to the question "Do you like math and number work at school?" was Yes (42.84\%), followed by Sometimes (41.88\%). A few participants (15.28\%) responded No. Further, controlled for baseline covariates (e.g., gender, ethnicity, and location), strata, and school random intercepts, there was a strong association between SES and Year 7 NAPLAN math achievement $(\square=.35,95 \%$ CI $[.31, .38])$.

We then predicted children's interest via Model 1 (no achievement scores), Model 2 (including achievement in Year 3, 5, and 7), and Model 3 (also including school average achievement for the children's Year 7 peers). Table 3 provides the results in log odds, the marginal effects for SES are provided in Figure 2. In Model 1, predicting children's math interest with SES reveals a positive association. Here the comparison was a $.59[.50, .67]$ probability of responding Yes to the math interest question for a high SES child compared to $.45[.37, .53]$ for a low SES child.

Including math performance in the Year 3, 5, and 7 NAPLAN tests resulted in the IDM consistent result (Model 2). Now the association between SES and math interest was negative. Here the comparison was a $.63[.55, .71]$ probability of responding Yes to the math interest question for a low SES child compared to $.51[.42, .60]$ an equally well performing high SES child. Finally, Model 3 resulted in the IDM predicted association of a nonsignificant relationship between SES and math interest. Importantly, the BFLPE was statistically significant (see Table 3). Taken together the results from Models 1-3 are consistent with Pattern 2; the prototypical IDM pattern of the associations of SES with math interests.

\section{Reading Interest}


The most common response to the question "Do you like reading work at school?" was Sometimes (45.27\%), followed by Yes $(42.88 \%)$. Few participants (11.85\%) responded No. Controlling for baseline covariates (e.g., gender, ethnicity, and location), strata, and school random intercepts, there was a strong association between SES and Year 7 NAPLAN reading achievement $(\square=.36,95 \% \mathrm{CI}[.32, .40])$.

As with math interest, we then fit Models 1-3 to predict children's responses to the reading interest question. Results are presented in Table 4 with the marginal effects for SES given in Figure 3. Here we observed a set of results that were more consistent with Pattern 3; the IDM with assimilation pattern. First, the association between SES and reading interest in Model 1 was larger (.22 probability difference) than the same association for math interest (.14 probability difference). Here the comparison was a $.46[.37, .55]$ probability of responding Yes to the reading interest question for a high SES child compared to .24 [.18, .31] for an equally well performing low SES child. In Model 2, the association did not turn negative but rather non-significant. Finally, in Model 3 the association was once again significant. Here, the comparison was a $.45[.35, .55]$ probability of responding Yes to the reading interest question for a high SES child compared to $.34[.25, .42]$ for an equally well performing low SES child in a school that performed equally well in the NAPLAN literacy test. This probability gap of .11 provides a potential estimation of SES assimilation in reading interest. Again, the BFLPE was statistically significant (see Table 4).

\section{Discussion}

The IDM integrates psychological and sociological processes to make a counterintuitive prediction that low SES children have an advantage over equal-achieving high SES children in academic interest, self-concept, and other forms of motivation in some contexts 
(Parker et al., 2018). The IDM focuses on school selection mechanisms and how such mechanisms activate the BFLPE. Controlling for prior-to-high-school selection, we found consistent evidence of the BFLPE for both math and reading interest. Our results are important in the context of BFLPE research because we used data from children's first year in a new school system (i.e., first year of high-school), we used high-stakes achievement tests that controlled for prior-to-school-selection achievement. In terms of the IDM, we outlined three potential patterns of relationships that could emerge from our Models 1-3. The patterns we entertained were: a) a null pattern of results that were inconsistent with IDM theory (Pattern 1); b) a prototypical IDM pattern (Pattern 2); and c) an IDM plus assimilation pattern (Pattern 3). We found evidence in favor of Pattern 2 for math interest, but the results were more in keeping with Pattern 3 for reading interest. Taken together, the models provide consistent evidence for the IDM. In addition, our results indicate that IDM processes are unlikely to be the only mechanism by which SES is related to academic interest — at least for reading interest.

\section{Social Contrast and Assimilation Processes in Academic Interest}

Looking at the math pattern of results alone, the IDM mechanisms are quite clear. Given the strong relationship between SES and achievement, there is a clear mechanism whereby children from high SES backgrounds have greater math interest because they perform better on math achievement tests. This is similar to the primary effect in Boudon's (1974) primary and secondary effects theory of the effect of SES on academic attainment. Boudon's (1974) theory of educational inequality distinguishes between primary (or achievement related) and secondary (or non-achievement related) pathways.

The secondary effect is thus the direct effect of SES on educational attainment, controlling for achievement. Boudon's work is consistent with the modern focus in much inequality work on direct effects of SES disadvantaged after controlling for educational 
attainment and achievement factors (Bukodi \& Goldthorpe, 2013, 2018; Gugushvili et al., 2017). The argument is that where achievement related factors are particularly resistant to intervention (particularly after early elementary school; Heckman, 2006), secondary effects might provide educational policy makers new levers to effect change. It is in this context that the IDM critical finding is so important. Comparing equally able lower SES children had greater academic interest than their higher SES peers. Put together with a) a significant BFLPE and b) a non-significant association between SES and math interest in Model 3 suggests that this pattern of association from favoring high SES children to favoring low SES children is due to the social contrast processes associated with the BFLPE. This is the exact set of relationships hypothesized by the IDM.

Reading interest differed from math interest. While the pattern in associations from Model 1-3 was similar in absolute size to math interest, SES had a positive association with reading interest in all cases. As we argued in the introduction, this sort of relationship is what we would expect to be present if there was an underlying and sufficiently large assimilation effect that operated in parallel to the IDM processes. Model 3 provides an estimate of the size of this assimilation process as an approximate difference in probability between a high SES and low SES child of .11 of responding Yes to our reading interest question (baseline probabilities of responding yes were approximately .40). It should be noted that our research design cannot discern what specific assimilation processes explain this difference. Indeed, it may not be an assimilation effect at all. For example, children's motivation responds to the quality of the instruction they receive (Guthrie \& Cox, 2001; Tsai et al., 2008). And the quality of instruction appears to be unequally distributed, likely favoring more advantaged schools (Goldhaber et al., 2015).

The natural question that these results raise is why does there remain a slight advantage for more advantaged children for reading but not for math interest in the models 
controlling for achievement at the student and school level? The relationship between SES and reading interest was larger than the same relationship with math interest in the initial model. This does not appear to be due to achievement processes introduced in Models 1 and 2. First, it is not due to differences in the relationship between SES and student level achievement where this relationship was almost as strong for both reading and math domains. Second, it is unlikely to be due to differences in BFLPE mechanisms as BFLPE estimates in the current sample, were not particularly different for math or reading domains. Further, a recent meta-analysis shows that BFLPE based on math and science domains versus reading domains were almost identical in size (Fang et al., 2018). This suggests an unmeasured process linking SES to interest such as differences in the strength of assimilation like processes or quality of instruction processes that are stronger for reading than for math.

One possibility is that reading and reading interest are more closely tied to capital and identity aspects of SES than is math. Although the widely cited '30 million word gap' is almost certainly an overestimation and ignores considerable variation among parents of similar SES, there are significant differences by SES in the number of pre-school parent-child vocal interactions and words spoken (Gilkerson et al., 2017). Regardless, it does appear that higher SES is associated with greater emphasis given to the importance of reading, and greater teacher-parent cooperation in emphasising the importance of reading (Lareau, 1987, 2011). From Bourdieusien perspective, reading is a form of cultural capital more readily available to higher SES children, more strongly instilled as a virtue by those in their social environment, and more clearly a feature of their habitus (see Sullivan, 2001 for a review). Lareau (2011, p.107) argues that higher SES families may "enjoy words for their own sake, ascribing an intrinsic pleasure to them" while lower SES families may view language in a more "functionalist fashion". If true, this may explain the stronger assimilation effect we found for reading interest than for math interest. Put simply, we suspect that reading is more 
closely tied to socioeconomic identity and cultural capital than math, yet this is speculation and would require empirical research to verify.

\section{Psychological Factors: Policy and Research}

We argue that our findings have several implications for the debate on academic selectivity. First, support for the IDM suggests that selectivity does not appear to benefit high SES children in terms of their academic interest (nor in some research do they even benefit academically; Dicke et al., 2018)— though selective schools appear to benefit high SES children in a range of other ways including via mechanisms such as social closure (Jerrim et al., 2016). The IDM highlights what Parker et al. (2019) call the Perverse Robin Hood effect that is associated with a stratified school system. Selective school systems activate the IDM thus giving children from lower SES backgrounds an advantage in self-beliefs and interest over equally able children from higher SES backgrounds. However, stratified school systems also lock children into more prescribed educational pathways that tend to work against children from lower SES backgrounds who (or whose family) tend to make less ambitious educational choices. Because of this, Parker et al. (2019) argue that stratification takes selfbelief and motivation advantages from the rich and gives them to the poor but it does so in a heavily prescribed environment that does not allow poorer children to make use of their advantage in terms of educational attainment.

A second conclusion is that researchers and policy makers should more critically evaluate psychological factors as candidates for interventions to reduce social inequalities. Not all psychological factors, nor all academic domains, are good intervention targets. At least for math, we found little evidence that low SES children suffered any deficit in academic interest compared to equally able high SES children. Likewise, context matters. Australia has about average levels of both social and achievement school stratification. As Parker et al. (2018) show stratification at this level and higher leads to the counter-intuitive 
IDM association between SES and some psychological constructs. Other countries with little stratification like Finland do not appear to have IDM-like effects. As such, the sorts of interventions that might be considered to boost interest in Finland versus Australia may well be different or target different groups of students. Taken together, researchers and policymakers need to be more discerning when promoting psychological skill as an answer to educational inequality.

\section{Limitations and Future Directions}

Working with archival data has both costs and benefits. LSAC provides access to a longitudinal representative sample of young children with survey responses integrated with government held educational administrative data. Access to data of such quality would not be possible with a primary data collection designed to address the aims of our specific research questions. While this is an enormous benefit, the use of LSAC also comes with costs. The biggest disadvantage of our use of archival data was the survey instruments. We only had single items for math and reading interest. That the results were consistent with our hypotheses given the lack of power that this single item represents is encouraging - though not surprising. This is because the domain space of academic interest is very narrow and concrete. Previous research shows that a single item can be sufficient in such cases (see, for example, supplementary analysis in Parker et al., 2012). Though it is important to note that a single item measure may struggle to distinguish interest from closely related constructs like enjoyment (Pekrun et al., 2019).

In addition, research has shown that measurement error would likely work against IDM processes by suppressing the size of BFLPE effect sizes (Dicke et al., 2018). Our measure of interest also had the disadvantage of having categories of only 'no', 'sometimes', and 'yes'. We modelled this question using a proportional odds model that hypothesizes a latent underlying continuous interest factor as a means of accounting for these few response 
options. The intuition underpinning proportional odds is that the Likert-like responses are a categorization of a continuous variable (Bürkner \& Vuorre, 2019). The fact that our findings were quite clear in support of the IDM with this measure is encouraging and we hypothesize that a multi-item measure of interest with more response options would have greater power and thus be more likely to support the IDM. Nevertheless, this is a hypothesis in need of further testing.

It is also worth noting that participants in this study were 12 years of age. This is important because BFLPEs tend to increase in size as children age (Marsh et al., 2015). As such, the IDM processes under investigation here may become even clearer in older samples. BFLPEs also tend to be larger at the class than at the school level (Marsh et al., 2014). The IDM is a model of school selection rather than class selection. However, in some countries where class selection is stratified by both SES and achievement, IDM processes may also operate at the class level. In such contexts, IDM research focused on the class level may be of interest.

In addition, it is important to note that academic interest is influenced by more frameof-reference processes than just the social comparison process of the BFLPE. For example, Marsh et al. (2020) show that academic interest is positively influenced by achievement in the same domain (e.g., math) but negatively influenced by achievement in very different academic domains (e.g., reading); an internal comparison process. Likewise, temporal comparisons (see Möller \& Marsh, 2013) may also influence interest (e.g., as I get better at a subject, I become more interested in it). Both temporal and internal comparison processes are within person mechanisms, so it is unclear whether they influence the IDM processes outlined here. All three processes, however, may be related to academic interest via academic self-concept. Future empirical research may want to consider the role of academic selfconcept as a mechanism of the processes identified here. 
Finally, it is worth noting that in some models Year 3 achievement had a negative influence on academic interest. This is almost certainly due to multicollinearity among Year 3, 5, and 7 achievement. We retained all achievement measures despite this as recent evidence (Bollinger \& Minier, 2015) suggests that inclusion of all proxies of a covariate (like underlying achievement) produces less biased estimates of focal parameters (in this case SES). These covariates appeared to have little impact on the results (see Figure 4).

\section{Conclusion}

Our research shows that the processes hypothesized by the IDM are present for young people, providing low SES youths with a small but significant advantage in math interest when compared to similarly able high SES youths. Though this is unlikely to offset the myriad of other challenges low SES children face from attending schools of lower average quality in stratified school systems. Our research highlights how sociological concerns, educational policy, and psychological concerns about social comparisons can uncover processes that disrupt expectations about what effect the structure of schools will have on children. Such research makes clear the need to consider the promise of psychological factors from a nuanced perspective. 


\section{References}

Akerlof, G. A., \& Kranton, R. E. (2005). Identity and the Economics of Organizations. Journal of Economic Perspectives, 19, 9-32.

https://doi.org/10.1257/0895330053147930

Akyol, Ş. P., Krishna, K., \& Wang, J. (2019). Taking PISA Seriously: How Accurate are Low Stakes Exams? (No. 24930; NBER Working Paper). NBER. https://www.nber.org/papers/w24930

Baker, K., Sipthorp, M., \& Edwards, B. (2017). A longitudinal measure of socioeconomic position in LSAC. Australian Institute of Family Studies. https://growingupinaustralia.gov.au/sites/default/files/tp18.pdf

Breen, R., \& Goldthorpe, J. H. (1997). Explaining Educational Differentials. Rationality and Society, 9, 275-305. https://doi.org/10.1177/104346397009003002

Bollinger, C. R., \& Minier, J. (2015). On the robustness of coefficient estimates to the inclusion of proxy variables. Journal of Econometric Methods, 4. https://doi.org/10.1515/jem-2012-0008

Boudon, R. (1974). Education, Opportunity and Social Inequality: Changing Prospects in Western Society (1st ed.). Wiley.

Bukodi, E, \& Goldthorpe, J. H. (2013). Decomposing "social origins": the effects of parents' class, status, and education on the educational attainment of their children. European Sociological Review, 29, 1024-1039. https://doi.org/10.1093/esr/jcs079

Bukodi, Erzsébet, \& Goldthorpe, J. H. (2018). Social mobility and education in britain: research, politics and policy. Cambridge University Press. https://doi.org/10.1017/9781108567404

Bürkner, P.-C., \& Vuorre, M. (2019). Ordinal regression models in psychology: A tutorial. Advances in Methods and Practices in Psychological Science, 2, 251524591882319. 
https://doi.org/10.1177/2515245918823199

Buuren, S. van, \& Groothuis-Oudshoorn, K. (2011). mice : Multivariate Imputation by Chained Equations in R. Journal of Statistical Software, 45. https://doi.org/10.18637/jss.v045.i03

Campbell, C., Proctor, H., \& Sherington, G. (2009). School Choice: How Parents Negotiate The New School Market In Australia. Allen \& Unwin.

Checchi, D., \& van de Werfhorst, H. G. (2018). Policies, skills and earnings: how educational inequality affects earnings inequality. Socio-Economic Review, 16, 137-160. https://doi.org/10.1093/ser/mwx008

Christensen, R. H. B. (2019). Ordinal - regression models for ordinal Sata (Version 2019.425) [Computer software]. CRAN. http://www.cran.r-project.org/package=ordinal/.

Dearden, L., McIntosh, S., Myck, M., \& Vignoles, A. (2000). The returns to academic, vocational and basic skills in Britain (No. 20; Skills Taskforce Research Paper). Department for Education and Employment.

Dicke, T., Marsh, H. W., Parker, P. D., Pekrun, R., Guo, J., \& Televantou, I. (2018). Effects of school-average achievement on individual self-concept and achievement: Unmasking phantom effects masquerading as true compositional effects. Journal of Educational Psychology, 110, 1112-1126. https://doi.org/10.1037/edu0000259

Eccles, J. S., \& Wigfield, A. (2002). Motivational beliefs, values, and goals. Annual Review of Psychology, 53, 109-132. https://doi.org/10.1146/annurev.psych.53.100901.135153

Eccles, J. S., \& Wigfield, A. (2020). From expectancy-value theory to situated expectancyvalue theory: A developmental, social cognitive, and sociocultural perspective on motivation. Contemporary Educational Psychology, 101859. https://doi.org/10.1016/j.cedpsych.2020.101859

Fang, J., Huang, X., Zhang, M., Huang, F., Li, Z., \& Yuan, Q. (2018). The Big-Fish-Little- 
Pond Effect on Academic Self-Concept: A Meta-Analysis. Frontiers in Psychology, 9, 1569. https://doi.org/10.3389/fpsyg.2018.01569

Gilkerson, J., Richards, J. A., Warren, S. F., Montgomery, J. K., Greenwood, C. R., Kimbrough Oller, D., Hansen, J. H. L., \& Paul, T. D. (2017). Mapping the Early Language Environment Using All-Day Recordings and Automated Analysis. American Journal of Speech-Language Pathology / American Speech-Language-Hearing Association, 26(2), 248-265. https://doi.org/10.1044/2016_AJSLP-15-0169

Goldhaber, D., Lavery, L., \& Theobald, R. (2015). Uneven playing field? assessing the teacher quality gap between advantaged and disadvantaged students. Educational Researcher, 44, 293-307. https://doi.org/10.3102/0013189X15592622

Goldthorpe, J. H. (2006). On Sociology Second Edition Volume One: 1 (2nd ed.). Stanford University Press.

Gugushvili, A., Bukodi, E., \& Goldthorpe, J. H. (2017). The direct effect of social origins on social mobility chances: 'glass floors' and 'glass ceilings' in britain. European Sociological Review, 33, 305-316. https://doi.org/10.1093/esr/jcx043

Guthrie, J. T., \& Cox, K. E. (2001). Classroom Conditions for Motivation and Engagement in Reading. Educational Psychology Review, 13, 283-302.

Guthrie, L. C., Butler, S. C., \& Ward, M. M. (2009). Time perspective and socioeconomic status: a link to socioeconomic disparities in health? Social Science \& Medicine, 68 , 2145-2151. https://doi.org/10.1016/j.socscimed.2009.04.004

Gutman, L. M., \& Schoon, I. (2016). A Synthesis of Causal Evidence Linking Non-Cognitive Skills to Later Outcomes for Children and Adolescents. In M. S. Khine \& S. Areepattamannil (Eds.), Non-cognitive Skills and Factors in Educational Attainment (pp. 171-198). SensePublishers. https://doi.org/10.1007/978-94-6300-591-39

Heckman, J. J. (2006). Skill formation and the economics of investing in disadvantaged 
children. Science, 312, 1900-1902. https://doi.org/10.1126/science.1128898

Hidi, S. (1990). Interest and its contribution as a mental resource for learning. Review of Educational Research, 60, 549-571. https://doi.org/10.3102/00346543060004549 Hidi, S., \& Renninger, K. A. (2006). The Four-Phase Model of Interest Development. Educational Psychologist, 41, 111-127. https://doi.org/10.1207/s15326985ep4102_4

Hyde, Janet S., \& Linn, M. C. (1988). Gender differences in verbal ability: A meta-analysis. Psychological Bulletin, 104, 53-69. https://doi.org/10.1037/0033-2909.104.1.53

Hyde, J S, Fennema, E., \& Lamon, S. J. (1990). Gender differences in mathematics performance: a meta-analysis. Psychological Bulletin, 107, 139-155. https://doi.org/10.1037/0033-2909.107.2.139

Jackson, M., Erikson, R., Goldthorpe, J. H., \& Yaish, M. (2007). Primary and secondary effects in class differentials in educational attainment. Acta Sociologica, 50, 211-229. https://doi.org/10.1177/0001699307080926

Jansen, M., Lüdtke, O., \& Schroeders, U. (2016). Evidence for a positive relation between interest and achievement: Examining between-person and within-person variation in five domains. Contemporary Educational Psychology, 46, 116-127. https://doi.org/10.1016/j.cedpsych.2016.05.004

Jerrim, J., Parker, P. D., Katyn Chmielewski, A., \& Anders, J. (2016). Private Schooling, Educational Transitions, and Early Labour Market Outcomes: Evidence from Three Anglophone Countries. European Sociological Review, 32, 280-294. https://doi.org/10.1093/esr/jcv098

Jerrim, J., \& Sims, S. (2019). How Do Academically Selective School Systems Affect Pupils' Social-Emotional Competencies? New Evidence From the Millennium Cohort Study. American Educational Research Journal, 000283121983096.

https://doi.org/10.3102/0002831219830965 
Koller, O., Baumert, J., \& Schnabel, K. (2001). Does Interest Matter? The Relationship between Academic Interest and Achievement in Mathematics. Journal for Research in Mathematics Education, 32, 448. https://doi.org/10.2307/749801

Kymlicka, W. (2009). Multicultural Odysseys: Navigating the New International Politics of Diversity. Oxford University Press.

Lareau, A. (1987). Social Class Differences in Family-School Relationships: The Importance of Cultural Capital. Sociology of Education, 60, 73. https://doi.org/10.2307/2112583 Lareau, A. (2011). Unequal Childhoods: Class, Race, And Family Life, 2nd Edition With An Update A Decade Later (2nd ed.). University Of California Press.

Maaz, K., Trautwein, U., Ldtke, O., \& Baumert, J. (2008). Educational Transitions and Differential Learning Environments: How Explicit Between-School Tracking Contributes to Social Inequality in Educational Outcomes. Child Development Perspectives, 2, 99-106. https://doi.org/10.1111/j.1750-8606.2008.00048.x

Marsh, H. W. (2007). Self-concept theory, measurement and research into practice: the role of self-concept in educational psychology. Vernon-Wall Lecture: British Psychological Society.

Marsh, H. W., Abduljabbar, A. S., Morin, A. J. S., Parker, P., Abdelfattah, F., Nagengast, B., \& Abu-Hilal, M. M. (2015). The big-fish-little-pond effect: Generalizability of social comparison processes over two age cohorts from Western, Asian, and Middle Eastern Islamic countries. Journal of Educational Psychology, 107, 258-271. https://doi.org/10.1037/a0037485

Marsh, H. W., Kong, C.-K., \& Hau, K.-T. (2000). Longitudinal multilevel models of the bigfish-little-pond effect on academic self-concept: Counterbalancing contrast and reflected-glory effects in Hong Kong schools. Journal of Personality and Social 
Psychology, 78, 337-349. https://doi.org/10.1037/0022-3514.78.2.337

Marsh, H. W., Kuyper, H., Morin, A. J. S., Parker, P. D., \& Seaton, M. (2014). Big-fish-littlepond social comparison and local dominance effects: Integrating new statistical models, methodology, design, theory and substantive implications. Learning and Instruction, 33, 50-66. https://doi.org/10.1016/j.learninstruc.2014.04.002

Marsh, H. W., \& Parker, J. W. (1984). Determinants of student self-concept: Is it better to be a relatively large fish in a small pond even if you don't learn to swim as well? Journal of Personality and Social Psychology, 47, 213-231. https://doi.org/10.1037//0022-

3514.47.1.213

Marsh, H. W., Parker, P. D., Guo, J., Basarkod, G., Niepel, C., \& Van Zanden, B. (2020). Illusory gender-equality paradox, math self-concept, and frame-of-reference effects: New integrative explanations for multiple paradoxes. Journal of Personality and Social Psychology. https://doi.org/10.1037/pspp0000306

Marsh, H. W., Seaton, M., Trautwein, U., Lüdtke, O., Hau, K. T., O’Mara, A. J., \& Craven, R. G. (2008). The Big-fish-little-pond-effect Stands Up to Critical Scrutiny: Implications for Theory, Methodology, and Future Research. Educational Psychology Review, 20, 319-350. https://doi.org/10.1007/s10648-008-9075-6

Marsh, H. W., Trautwein, U., Lüdtke, O., Köller, O., \& Baumert, J. (2005). Academic self-concept, interest, grades, and standardized test scores: reciprocal effects models of causal ordering. Child Development, 76, 397-416. https://doi.org/10.1111/j.1467$\underline{8624.2005 .00853 . x}$

Möller, J., \& Marsh, H. W. (2013). Dimensional comparison theory. Psychological Review, 120, 544-560. https://doi.org/10.1037/a0032459

Morin, A. J. S., Marsh, H. W., Nagengast, B., \& Scalas, L. F. (2014). Doubly latent multilevel analyses of classroom climate: an illustration. The Journal of Experimental 
Education, 82, 143-167. https://doi.org/10.1080/00220973.2013.769412

Murphy, R., \& Weinhardt, F. (2020). Top of the class: the importance of ordinal rank. The Review of Economic Studies. https://doi.org/10.1093/restud/rdaa020

Norton, A., \& Monahan, K. (2015). Wave 6 Weighting and Non-Response. Australian Government Department of Social Services. https://growingupinaustralia.gov.au/sites/default/files/tp15.pdf

OECD. (2019). Balancing school choice and equity: an international perspective based on pisa. OECD. https://doi.org/10.1787/2592c974-en

Parker, P., Dicke, T., Guo, J., \& Marsh, H. (2019). A macro context theory of academic selfconcept: Ability stratification and the big-fish-little-pond effect. https://doi.org/10.31234/osf.io/bwy59

Parker, P., Guo, J., \& Sanders, T. (2019). Socioeconomic inequality and student outcomes in australia. In L. Volante, S. V. Schnepf, J. Jerrim, \& D. A. Klinger (Eds.), Socioeconomic Inequality and Student Outcomes: Cross-National Trends, Policies, and Practices (Vol. 4, pp. 189-204). Springer Singapore. https://doi.org/10.1007/978-981-13-9863-6_11

Parker, P. D., Marsh, H. W., Guo, J., Anders, J., Shure, N., \& Dicke, T. (2018). An information distortion model of social class differences in math self-concept, intrinsic value, and utility value. Journal of Educational Psychology, 110, 445-463. https://doi.org/10.1037/edu0000215

Parker, P. D., Van Zanden, B., Marsh, H. W., Owen, K., Duineveld, J. J., \& Noetel, M. (2019). The Intersection of Gender, Social Class, and Cultural Context: a MetaAnalysis. Educational Psychology Review. https://doi.org/10.1007/s10648-019-09493-1

Parker, P. D., Van Zanden, B., \& Parker, R. B. (2017). Girls get smart, boys get smug: Historical changes in gender differences in math, literacy, and academic social comparison and achievement. Learning and Instruction. 


\section{https://doi.org/10.1016/j.learninstruc.2017.09.002}

Parker, P. D., Schoon, I., Tsai, Y.-M., Nagy, G., Trautwein, U., \& Eccles, J. S. (2012).

Achievement, agency, gender, and socioeconomic background as predictors of postschool choices: a multicontext study. Developmental Psychology, 48, 1629-1642. $\underline{\text { https://doi.org/10.1037/a0029167 }}$

Parker, P. D., Jerrim, J., Schoon, I., \& Marsh, H. W. (2016). A Multination Study of Socioeconomic Inequality in Expectations for Progression to Higher Education: The Role of Between-School Tracking and Ability Stratification. American Educational Research Journal, 53, 6-32. https://doi.org/10.3102/0002831215621786

Pekrun, R. (2019). The murky distinction between curiosity and interest: state of the art and future prospects. Educational Psychology Review, 31, 905-914.

\section{https://doi.org/10.1007/s10648-019-09512-1}

Reardon, S. F. (2011). The widening academic achievement gap betweenthe rich and the poor: New evidence and possible explanations. In R. Murnane \& G. Duncan (Eds.), Whither OpportunityRising Inequality and the Uncertain Life Chances of Low-Income Children (pp. 91-116). Russell Sage Foundation.

Ryan, R. M., \& Deci, E. L. (2000). Self-determination theory and the facilitation of intrinsic motivation, social development, and well-being. The American Psychologist, 55, 68-78. https://doi.org/10.1037/0003-066X.55.1.68

Salchegger, S. (2016). Selective school systems and academic self-concept: How explicit and implicit school-level tracking relate to the big-fish--little-pond effect across cultures. Journal of Educational Psychology, 108, 405-423. https://doi.org/10.1037/edu0000063

Sanson, A., Nicholson, J., Ungerer, J., Zubrick, S., Wilson, K., Ainley, J., Berthelsen, D., Bittman, M., Broom, D., Harrison, L., Rodgers, B., Sawyer, M., Silburn, S., Stazdins, L., Vimpani, G., \& Wake, M. (2002). Introducing the Longitudinal Study of Australian 
Children. Australian Institute of Family Studies.

Schiefele, U., Krapp, A., \& Winteler, A. (1992). Interest as a predictor of academic achievement: A meta-analysis of research. . In K. A. Renninger, S. Hidi, \& A. Krapp (Eds.), The role of interest in learning and development (pp. 183-212). Lawrence Erlbaum Associates, Inc.

Steegen, S., Tuerlinckx, F., Gelman, A., \& Vanpaemel, W. (2016). Increasing transparency through a multiverse analysis. Perspectives on Psychological Science: A Journal of the Association for Psychological Science, 11, 702-712.

https://doi.org/10.1177/1745691616658637

Sullivan, A. (2001). Cultural capital and educational attainment. Sociology, 35, 893912. https://doi.org/10.1017/S0038038501008938

Sweller, N., Graham, L. J., \& Van Bergen, P. (2012). The minority report: disproportionate representation in australia's largest education system. Exceptional Children, 79, 107125. https://doi.org/10.1177/001440291207900106

Swift, D. F. (1966). Social class and achievement motivation. Educational Research, 8(2), 83-95. https://doi.org/10.1080/0013188660080202

The Smith Family. (2016). Improving the educational outcomes of disadvantaged young Australians. The Smith Family.

Tsai, Y.-M., Kunter, M., Lüdtke, O., Trautwein, U., \& Ryan, R. M. (2008). What makes lessons interesting? The role of situational and individual factors in three school subjects. Journal of Educational Psychology, 100, 460-472. https://doi.org/10.1037/0022-0663.100.2.460

Xu, J. (2018). Reciprocal effects of homework self-concept, interest, effort, and math achievement. Contemporary Educational Psychology, 55, 42-52.

https://doi.org/10.1016/j.cedpsych.2018.09.002 
Zell, E., Strickhouser, J. E., \& Alicke, M. D. (2017). Local dominance effects on selfevaluations and intrinsic motivation. Self and Identity, 16, 629-644.

https://doi.org/10.1080/15298868.2017.1295100

Zell, E., Strickhouser, J. E., \& Alicke, M. D. (2017). Local dominance effects on selfevaluations and intrinsic motivation. Self and Identity, 16, 629-644.

https://doi.org/10.1080/15298868.2017.1295100 


\section{Tables and Figures}

Table 1

Descriptives

\begin{tabular}{|c|c|c|c|c|c|}
\hline Year & Variable & Mean & SD & ICC & Distribution \\
\hline Age 4 & Girl & $48.9 \%$ & & 0.199 & \\
\hline Age 4 & Indigenous & $1.8 \%$ & & 0.176 & \\
\hline Age 4 & LOTE $^{1}$ & $13.0 \%$ & & 0.249 & \\
\hline Year 3 (Age 8) & math achievement & -0.015 & 0.998 & 0.102 & \\
\hline Year 5 (Age 10) & math achievement & -0.008 & 1.006 & 0.140 & \\
\hline Year 7 (Age 12) & math achievement & -0.015 & 1.001 & 0.190 & \\
\hline Year 7 (Age 12) & math interest:No & $15.3 \%$ & & $-0.020^{2}$ & \\
\hline Year 7 (Age 12) & math interest:Sometimes & $41.9 \%$ & & 0.001 & \\
\hline Year 7 (Age 12) & math interest:Yes & $42.8 \%$ & & 0.034 & \\
\hline Year 3 (Age 8) & reading achievement & -0.019 & 1.009 & 0.174 & \\
\hline Year 5 (Age 10) & reading achievement & -0.011 & 1.006 & 0.131 & \\
\hline Year 7 (Age 12) & reading achievement & -0.007 & 1.004 & 0.175 & \\
\hline Year 7 (Age 12) & reading interest:No & $11.8 \%$ & & $-0.003^{2}$ & \\
\hline Year 7 (Age 12) & reading interest:Sometimes & $45.3 \%$ & & 0.020 & \\
\hline Year 7 (Age 12) & reading interest:Yes & $42.9 \%$ & & 0.049 & \\
\hline Year 7 (Age 12) & school average math achievement & -0.006 & 1.001 & & \\
\hline Year 7 (Age 12) & school average reading achievement & -0.005 & 1.007 & & \\
\hline Age 4 & SES $^{3}$ & 0.145 & 0.978 & 0.308 & \\
\hline
\end{tabular}

${ }^{1}$ LOTE = Language Other Than English

${ }^{2}$ ICCs have negative values due to the extremely low variance

${ }^{3} \mathrm{SES}=$ Socioeconomic Status 
Table 2

Correlations Among Study Variables for Reading (Lower Triangle) and Math (Upper Triangle)

Math Correlations

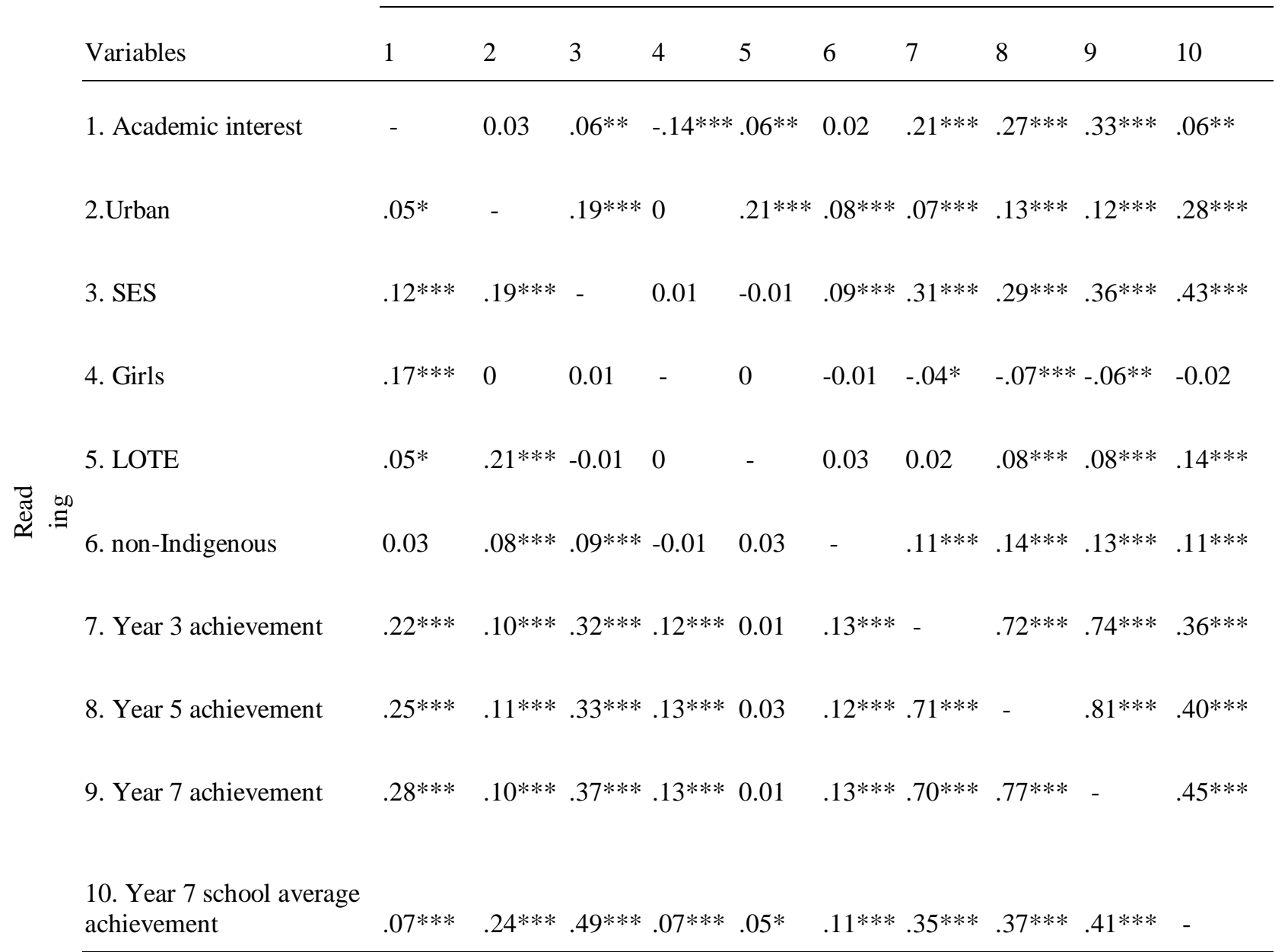

Note. Correlation among the reading variables on the bottom triangle. Correlation among the math variables on the upper triangle. $* \mathrm{p}<0.05 ; * * \mathrm{p}<0.01 ; * * * \mathrm{p}<0.001$ 
Table 3

Models Predicting Math Interest

\begin{tabular}{|c|c|c|c|c|c|c|c|c|c|c|c|c|}
\hline \multirow[b]{2}{*}{ Predictor } & \multicolumn{4}{|c|}{ Model 1} & \multicolumn{4}{|c|}{ Model 2} & \multicolumn{4}{|c|}{ Model 3} \\
\hline & Log-odds & CI $2.5 \%$ & CI $97.5 \%$ & $\mathrm{p}$ & Log-odds & CI $2.5 \%$ & CI $97.5 \%$ & $\mathrm{p}$ & Log-odds & CI $2.5 \%$ & CI $97.5 \%$ & $\mathrm{p}$ \\
\hline No| Sometimes & -1.42 & -2.05 & -0.78 & $>0.001$ & -2.18 & -2.85 & -1.51 & $>0.001$ & -2.17 & -2.84 & -1.5 & $>0.001$ \\
\hline Sometimes|Yes & 0.67 & 0.04 & 1.30 & 0.040 & 0.13 & -0.53 & 0.79 & 0.71 & 0.15 & -0.51 & 0.81 & 0.66 \\
\hline SES & 0.14 & 0.06 & 0.22 & $>0.001$ & -0.13 & -0.22 & -0.04 & 0.01 & -0.07 & -0.16 & 0.03 & 0.17 \\
\hline Y3 Math Ach. & & & & & -0.14 & -0.28 & -0.01 & 0.04 & -0.14 & -0.28 & -0.01 & 0.04 \\
\hline Y5 Math Ach. & & & & & 0.14 & -0.01 & 0.29 & 0.07 & 0.15 & 0.00 & 0.31 & 0.05 \\
\hline Y7 Math Ach. & & & & & 0.81 & 0.64 & 0.98 & 0.01 & 0.88 & 0.7 & 1.05 & $>0.001$ \\
\hline \multicolumn{5}{|c|}{ Y7 Sch. Avg. Math Ach (BFLPE) } & & & & & -0.24 & -0.34 & -0.13 & $>0.001$ \\
\hline Urban & -0.02 & -0.26 & 0.21 & 0.85 & -0.08 & -0.32 & 0.17 & 0.54 & -0.03 & -0.28 & 0.22 & 0.80 \\
\hline Gender (Girl) & -0.54 & -0.70 & -0.39 & 0.001 & -0.49 & -0.66 & -0.33 & $>0.001$ & -0.5 & -0.66 & -0.34 & $>0.001$ \\
\hline LOTE & 0.41 & 0.17 & 0.65 & 0.001 & 0.25 & -0.00 & 0.5 & 0.05 & 0.28 & 0.03 & 0.54 & 0.03 \\
\hline non-Indigenous & 0.29 & -0.27 & 0.86 & 0.31 & -0.27 & -0.86 & 0.32 & 0.37 & -0.24 & -0.82 & 0.35 & 0.43 \\
\hline AIC & & & & 5035 & & & & 4720 & & & & 4701 \\
\hline $\mathrm{BIC}$ & & & & 5204 & & & & 4906 & & & & 4893 \\
\hline Model Compariso & & & & & M2 & vs M1: & $2(3)=106$ & $p<.001$ & & M2 vs M1: & $\square^{2}(1)=6, l$ & $p<.001$ \\
\hline
\end{tabular}

Note. SES = socioeconomic Status, Y = Year in school, Ach. = Achievement score on NAPLAN test, Avg. = Average, Sch. $=$ school, LOTE $=$ Language other than English spoken at home. Shaded rows are critical rows for our analysis. Highlighted key estimates. BFLPE = Big-fish-little-pond effect.

Table 4

Models Predicting Reading Interest

\begin{tabular}{|c|c|c|c|c|c|c|c|c|c|c|c|c|}
\hline \multirow[b]{2}{*}{ Predictor } & \multicolumn{4}{|c|}{ Model 1} & \multicolumn{4}{|c|}{ Model 2} & \multicolumn{4}{|c|}{ Model 3} \\
\hline & Log-odds & CI $2.5 \%$ & CI $97.5 \%$ & $\mathrm{p}$ & Log-odds & CI $2.5 \%$ & CI $97.5 \%$ & $\mathrm{p}$ & Log-odds & CI $2.5 \%$ & CI $97.5 \%$ & $\mathrm{p}$ \\
\hline No| Sometimes & -1.58 & -2.25 & -0.91 & 0.001 & -2.09 & -2.78 & -1.39 & 0.001 & -2.04 & -2.74 & -1.35 & 0.001 \\
\hline Sometimes|Yes & 0.86 & 0.19 & 1.52 & 0.010 & 0.47 & -0.21 & 1.16 & 0.18 & 0.52 & -0.16 & 1.21 & 0.14 \\
\hline SES & 0.25 & 0.16 & 0.33 & 0.001 & 0.06 & -0.03 & 0.15 & 0.19 & 0.13 & 0.03 & 0.22 & 0.01 \\
\hline Y3 Reading Ach. & & & & & -0.01 & -0.13 & 0.12 & 0.92 & 0.00 & -0.12 & 0.13 & 0.98 \\
\hline Y5 Reading Ach. & & & & & 0.22 & 0.07 & 0.36 & 0.01 & 0.23 & 0.08 & 0.37 & 0.001 \\
\hline Y7 Reading Ach. & & & & & 0.37 & 0.22 & 0.51 & 0.001 & 0.40 & 0.26 & 0.55 & 0.001 \\
\hline \multicolumn{5}{|c|}{ Y7 Sch. Avg. Reading Ach (BFLPE) } & & & & & -0.19 & -0.29 & -0.09 & 0.001 \\
\hline Urban & -0.04 & -0.28 & 0.21 & 0.760 & -0.09 & -0.34 & 0.16 & 0.49 & -0.05 & -0.30 & 0.20 & 0.68 \\
\hline Gender (Girl) & 0.65 & 0.49 & 0.81 & 0.001 & 0.55 & 0.38 & 0.71 & 0.001 & 0.56 & 0.40 & 0.72 & 0.001 \\
\hline LOTE & 0.24 & 0.00 & 0.49 & 0.05 & 0.25 & 0.00 & 0.50 & 0.05 & 0.25 & 0.00 & 0.50 & 0.05 \\
\hline non-Indigenous & 0.15 & -0.45 & 0.76 & 0.62 & -0.16 & -0.79 & 0.46 & 0.60 & -0.12 & -0.74 & 0.50 & 0.0 \\
\hline AIC & & & & 4812 & & & & 4669 & & & & 4658 \\
\hline BIC & & & & 4981 & & & & 4856 & & & & 4850 \\
\hline
\end{tabular}


Note. SES $=$ Socioeconomic Status, $\mathrm{Y}=$ Year in school, Ach. $=$ Achievement score on NAPLAN test, Avg. = Average, Sch.$=$ school, LOTE $=$ Language other than English spoken at home. Shaded rows are critical rows for our analysis. Highlighted key estimates. BFLPE $=$ Big-fish-little-pond effect. 
Figure 1. The relationship between socioeconomic (SES) and achievement stratification in PISA 2012 countries.

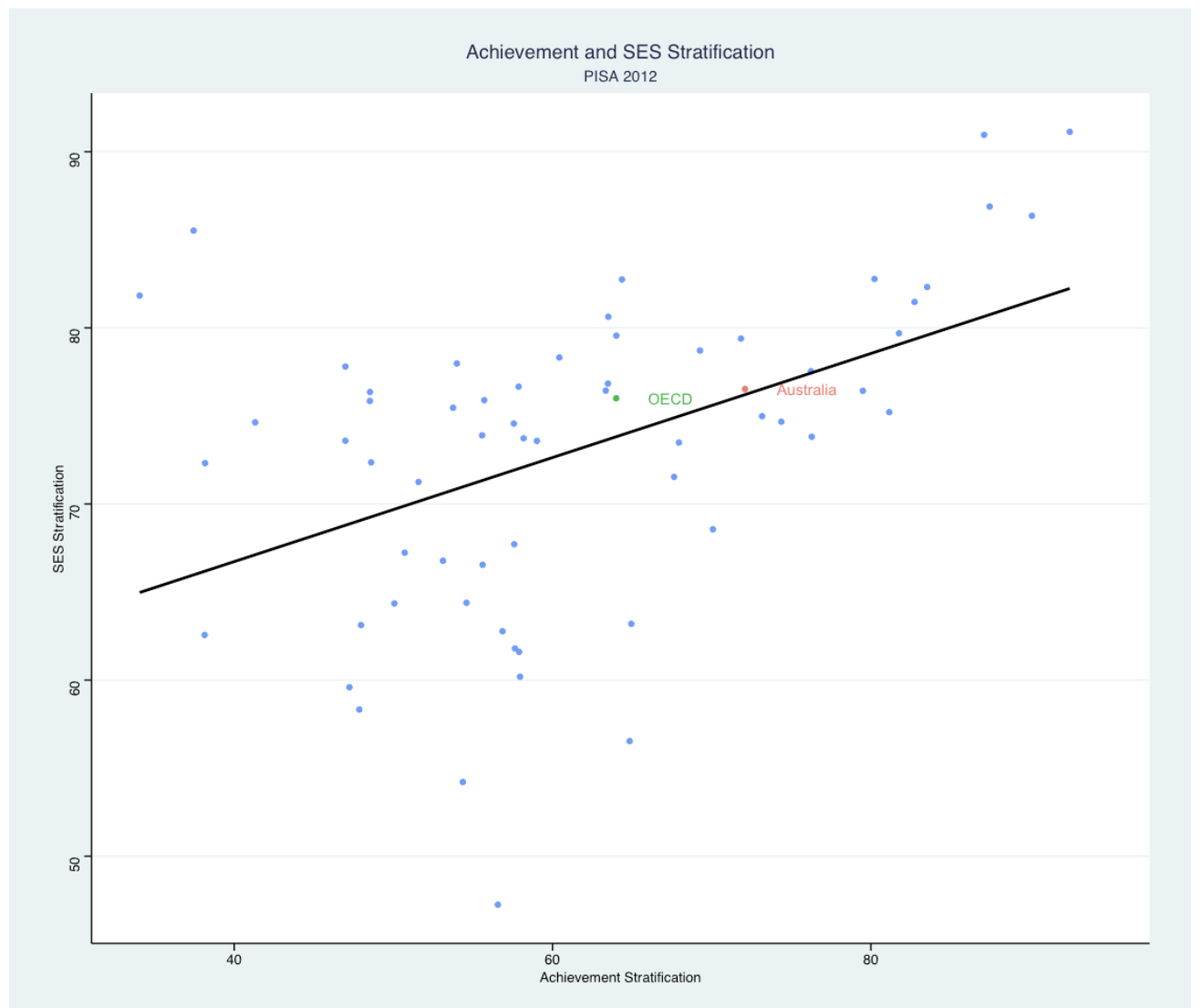

Notes. Taken from estimates in (OECD, 2019). PISA = Programme for International Student Assessment. OECD (Organisation for Economic Cooperation and Development) average and Australian estimates highlighted. Figure used by permission under the MIT License. 
Figure 2. Marginal effects for Year 7 math interest.

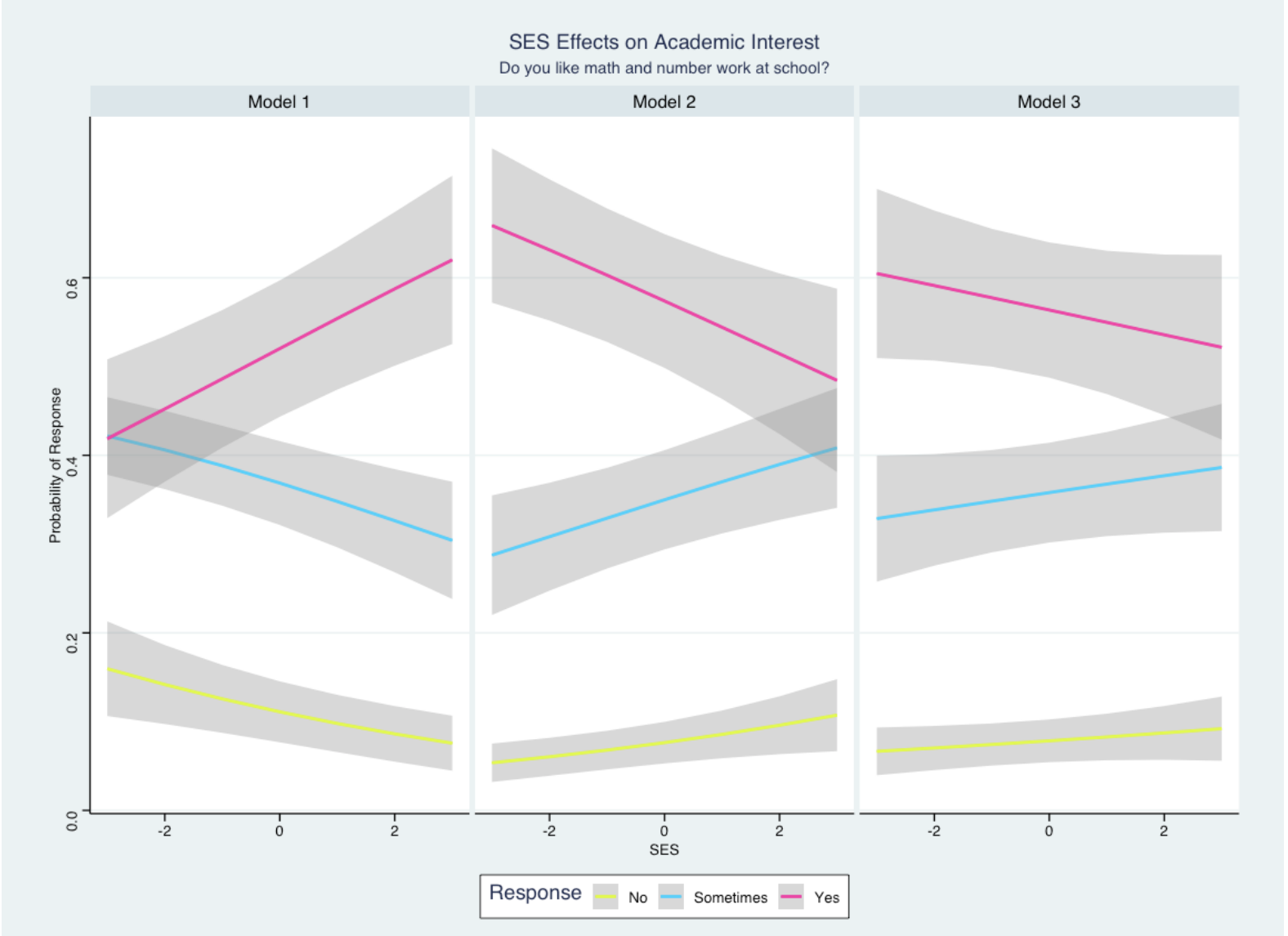

Note. Marginal probabilities are calculated at the average of all covariates. Figure used by permission under the MIT License. 
Figure 3. Marginal effects for Year 7 reading interest

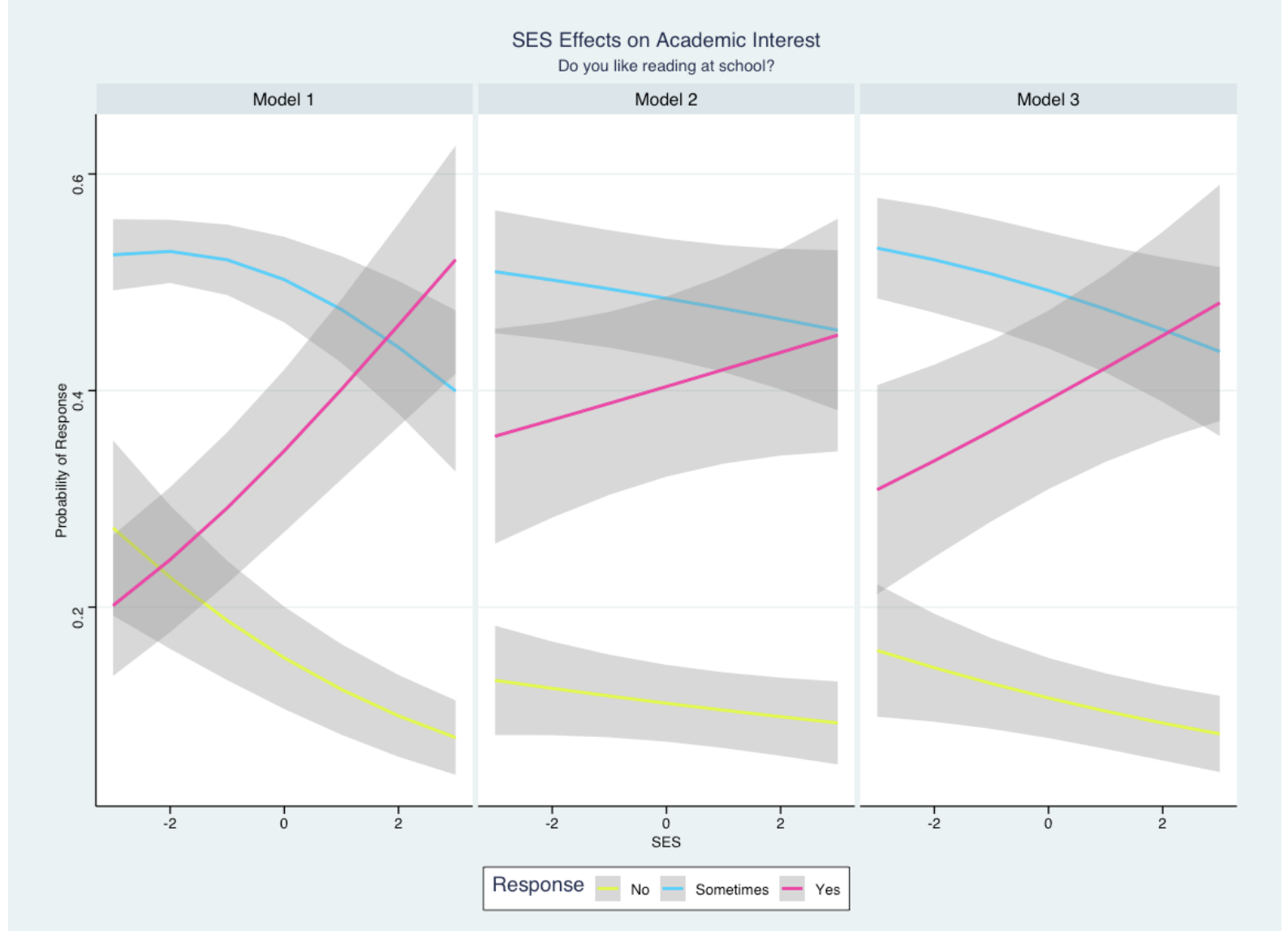

Note. Marginal probabilities are calculated at the average of all covariates. Figure used by permission under the MIT License. 
Figure 4. Multiverse analysis of Models 1-3.

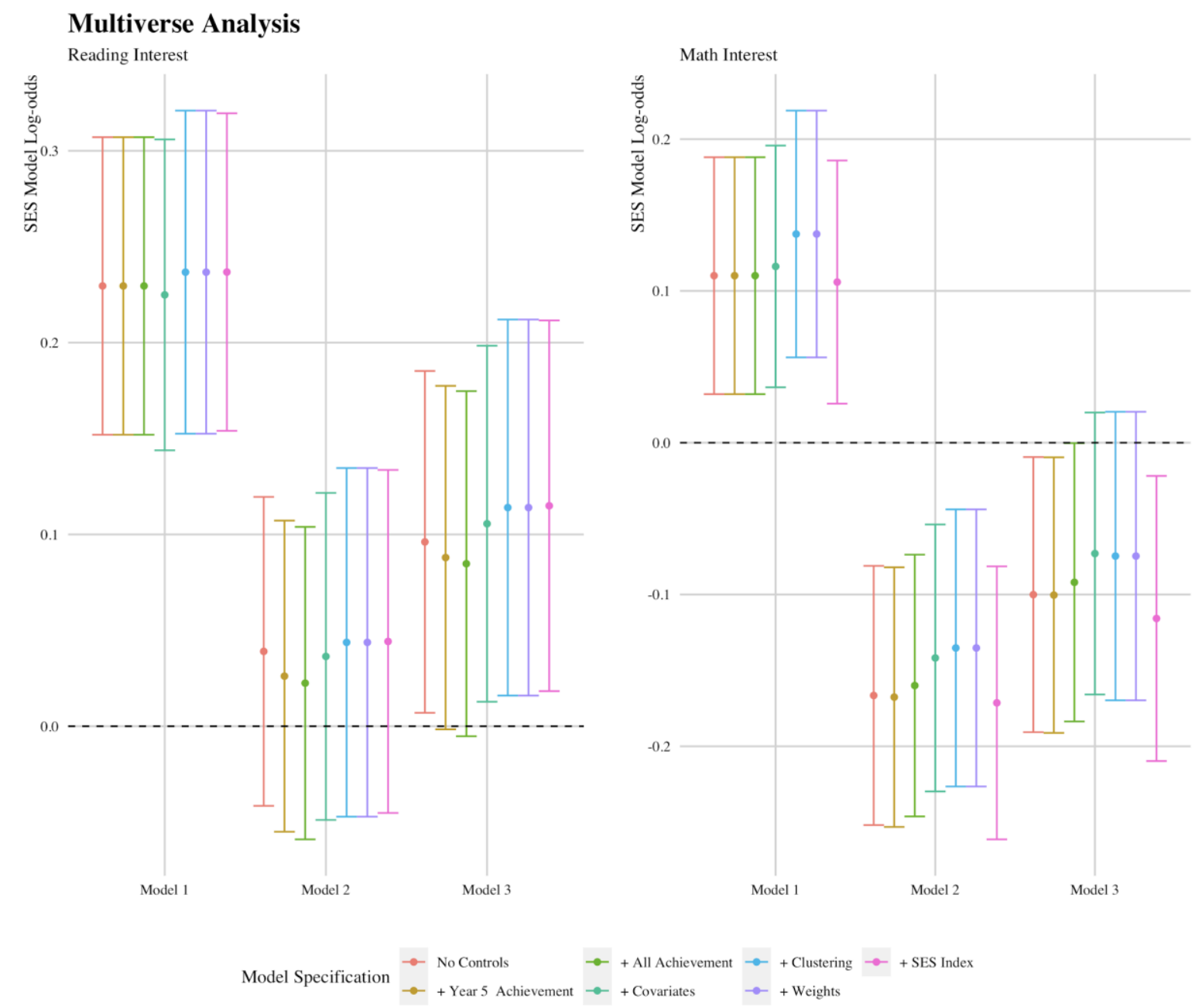

Notes. Specifications refer to different model set-ups. Models progress from no controls, no weights, no accounting for clustering to progressively adding these components to the model. Models that do not include random effects for schools instead use cluster robust standard errors. All achievement refers to including achievement scores from both Year 3 and Year 5. + SES Index refers to an index of SES scores taken from participants' parents at the child's age 4, 8, and 10. Due to the Great Recession SES from age 8 and 10 were more poorly related to school selection. Figure used by permission under the MIT License. 


\section{Appendix}

Table A1

Test of Proportional Odds Assumption

\begin{tabular}{lll}
\hline Model & Math $\Delta$ LOOIC(SE) & Reading $\Delta$ LOOIC(SE) \\
\hline Model 1 & $0.0(1.0)$ & $-0.5(1.0)$ \\
Model 2 & $-0.5(0.7)$ & $-2.1(1.0)$ \\
Model 3 & $-1.9(0.8)$ & $-0.5(1.0)$ \\
\hline
\end{tabular}

Note. Test of proportional odds assumption was done by comparing a model with and without category specific effects for SES. LOOIC is the leave-one-out information criteria. $\Delta$ is the difference between a model with and without category specific effects of SES. 